\title{
Missing the mark: Current practices in teaching the male urogenital examination to Canadian undergraduate medical students
}

\author{
Kristen McAlpine, MD; Stephen Steele, MD, FRCSC
}

Department of Urology, Queen's University, Kingston, ON, Canada

Cite as: Can Urol Assoc J 2016; 10(7-8):281-5. hittp://dx.doi.org/10.5489/cuai.3679

\section{Abstract}

Introduction: The urogenital physical examination is an important aspect of patient encounters in various clinical settings. Introductory clinical skills sessions are intended to provide support and alleviate students' anxiety when learning this sensitive exam. The techniques each Canadian medical school uses to guide their students through the initial urogenital examination has not been previously reported. Methods: This study surveyed pre-clerkship clinical skills program directors at the main campus of English-speaking Canadian medical schools regarding the curriculum they use to teach the urogenital examination.

Results: A response rate of $100 \%$ was achieved, providing information on resources and faculty available to students, as well as the manner in which students were evaluated. Surprisingly, over onethird of the Canadian medical schools surveyed failed to provide a setting in which students perform a urogenital examination on a patient in their pre-clinical years. Additionally, there was no formal evaluation of this skill set reported by almost $50 \%$ of Canadian medical schools prior to clinical training years.

Conclusions: To ensure medical students are confident and accurate in performing a urogenital examination, it is vital they be provided the proper resources, teaching, and training. As we progress towards a competency-based curriculum, it is essential that increased focus be placed on patient encounters in undergraduate training. Further research to quantify students' exposure to the urogenital examination during clinical years would be of interest. Without this commitment by Canadian medical schools, we are doing a disservice not only to the medical students, but also to our patient population.

\section{Introduction}

The ability to accurately perform a urogenital examination is an essential skill for physicians in many disciplines. Patients with urinary or genital complaints may eventually require assessment by a urologist, however, the initial physical examination is typically performed by doctors in other specialties. Patient presentations requiring examination of the genitalia are routinely seen in the fields of family medicine, pediatrics, surgery, and emergency medicine.

As medical students enter the clinical years of their training, they require the capacity to perform a comprehensive urogenital physical examination. Studies have shown that the greatest factor in predicting medical students' ability to confidently complete a genital examination at the time of graduation is the total number of exams performed during the clinical years of their training. ${ }^{1}$ This practical experience can vary significantly, influenced by each student's clinical rotations, gender, and career orientation. ${ }^{1,2}$ Despite various efforts by medical educators to provide a universal level of training, medical students are often unsure of their competence to perform a genital examination as they enter residency. ${ }^{2}$

The introduction to sensitive physical examinations including breast, female pelvic, male genital, and digital rectal exams - has repeatedly been found to induce stress and anxiety in medical students. ${ }^{3-6}$ The personal nature of these encounters, as well as the fear of inflicting pain or harm, contribute to students' hesitancy. ${ }^{6}$ Medical educators face the challenging task of developing well-supported clinical skills sessions to introduce these sensitive exams. Balancing the professional maturity of a cohort of students with the necessity to learn societally complex examination skills requires significant coordination and planning.

Various approaches have been used to ease students into their first opportunity to perform a genital examination. A recent international study was undertaken to investigate trends in the teaching of sensitive physical examinations to medical students across Western countries. ${ }^{7}$ The use of mannequins to simulate patient anatomy was the most widely used technique. ${ }^{7}$ An increasingly common method to teach sensitive examinations is the inclusion of genital teaching associates (GTAs) in clinical skills sessions. ${ }^{7}$ GTAs are paid community members who are taught the proper approach to a genital examination. They are examined by students during teaching sessions and provide real-time feedback during the 
McAlpine et al.

encounter. ${ }^{7}$ Their use has been shown to improve students comfort and confidence with genital examinations. ${ }^{5}$

The development of online resources and medical simulation has also allowed educators to provide preparatory material for students prior to their initial patient encounter. A study by Ronn et al in 2012 found that watching an online demonstration of the female pelvic examination immediately prior to performing the exam greatly improves students' comfort and objective ability. ${ }^{8}$ Recently, even virtual encounters with digital humans to precede patient contact have been explored. ${ }^{9}$

Although various methods to teach sensitive physical examinations have been described, no investigation has compared current practices in teaching the male urogenital examination within Canada. This study was designed to review current practices in this teaching and to identify where future educational focus may be applied to improve students' ability and confidence by the time of graduation.

\section{Methods}

A nine-question, online survey was developed to assess various aspects of the genitourinary clinical skills curriculum (Appendix 1). Approval from the Health Science Research and Ethics Board at Queen's University was obtained prior to contacting potential participants. Contact was made between July and September 2014 to the individual most responsible for coordinating the pre-clerkship urogenital clinical skills curriculum at each of the 14 English-speaking Canadian medical schools' main campus. These individuals were felt to be the most knowledgeable regarding the details of their school's introductory male urogenital examination clinical skills sessions. Descriptive analysis of the survey results was undertaken once all participants had submitted the online questionnaire.

\section{Results}

All 14 questionnaires were returned using the online survey. Medical students at all 14 schools learn the urogenital examination initially in the first two years of their training. Of the 14 schools, 10 (71\%) introduce the examination in the second year of the undergraduate program and four schools (29\%) in the first year (Fig. 1).

Each medical school offers introductory clinical skills sessions in small-group seminars $(79 \%)$ or individual meetings with direct tutor guidance (21\%). No school solely offers lecture-based curriculum to teach the urogenital examination.

Students' preparatory and reference material varies between schools. Clinical skills textbooks and handbooks are available at $43 \%(6 / 14)$ and $50 \%$ (7/14) of medical schools, respectively. Online videos are provided by $50 \%$ (7/14) of schools and a full online module at one school (7\%). Lecture slides, urology department handouts, and presession briefing by a surgical resident are also resources offered at various schools.

Urogenital clinical skills sessions are taught by a variety of medical professionals (Fig. 2). Urologists were actively involved at nine of the 14 medical schools during the clinical skills sessions.

During introductory sessions, students at 10 of 14 medical schools practice their examination skills on mannequins or models of the prostate and/or male genitalia. Standardized patients are examined at four of 14 medical schools (29\%).

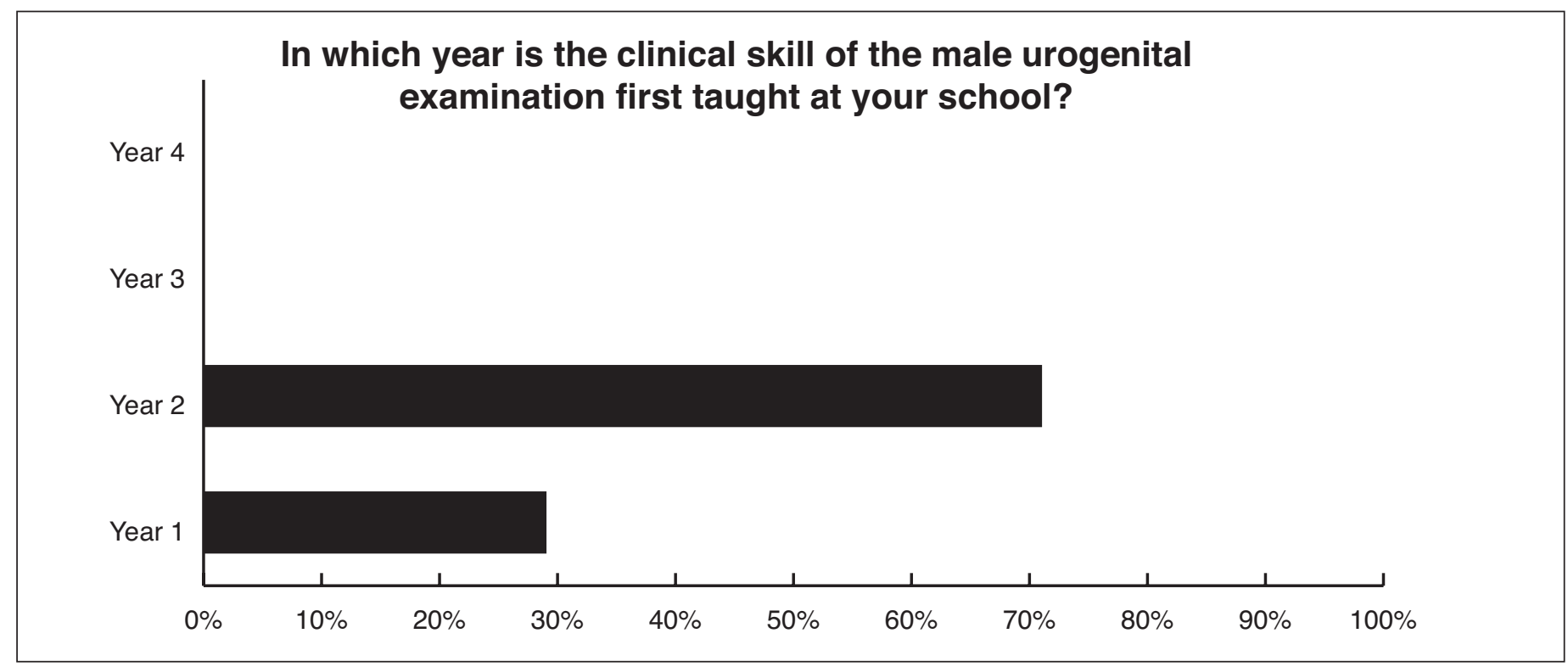

Fig. 1. Timing of initial clinical skills sessions. 


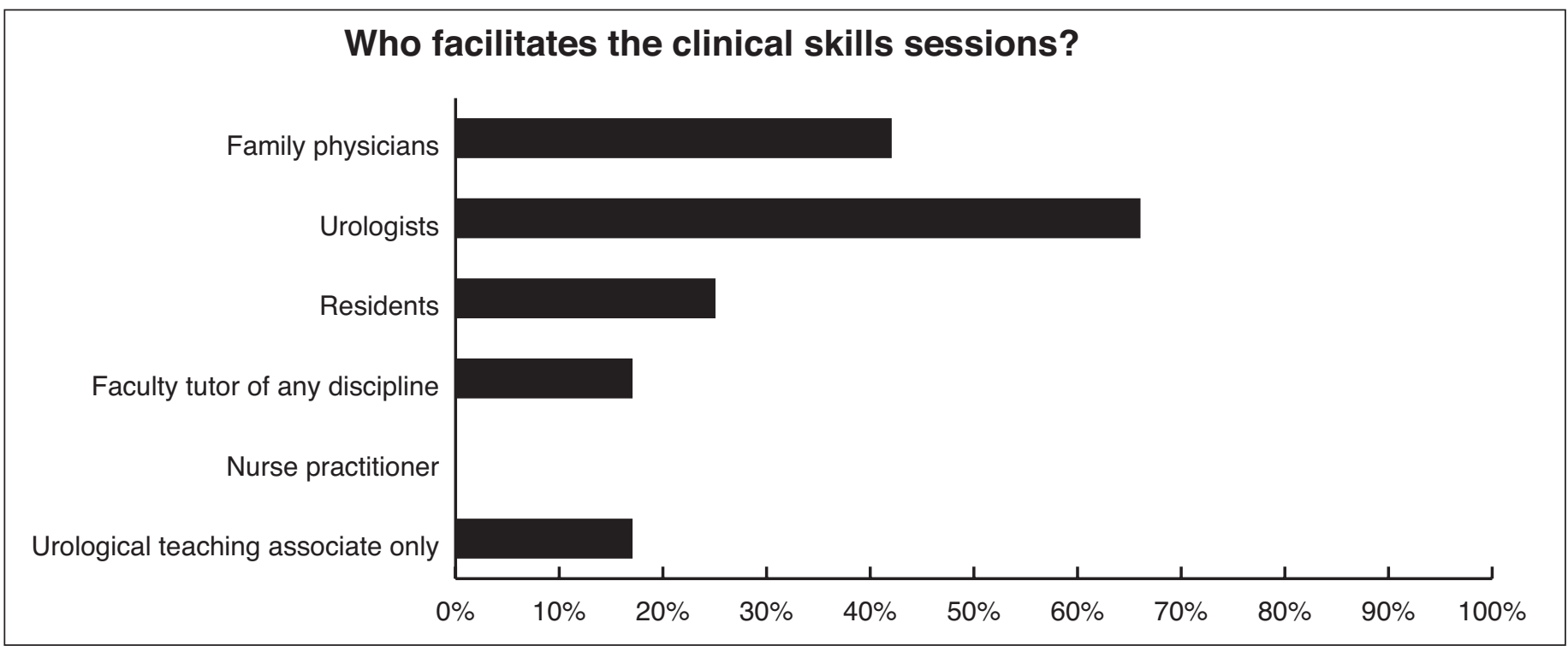

Fig. 2. Facilitators for urogenital clinical skills sessions.

Genital teaching associates are present during five medical schools clinical skills sessions (36\%). At one school, students examine cadavers during introductory urogenital clinical skills sessions.

Students' evaluation on the information provided in clinical skills sessions varies. Students are explicitly not evaluated on this material at $43 \%$ of schools (6/14). Reflective exercises and formative feedback were also reported at $7 \%$ and $21 \%$ of schools, respectively. Students at five of 14 schools may have the urogenital examination as part of a clinical examination (i.e., an objective structured clinical examination [OSCE]). Students at three schools are tested on aspects of the urogenital physical examination during written finals.

Following introductory clinical skills sessions, none of the surveyed individuals reported knowledge of formal teaching sessions offered to all medical students at their school. Students have the potential for further formal teaching in a clinical setting at 12 of 14 (86\%) schools. This was dependent on their clinical rotation schedule. At two of 14 (14\%) schools, students do not have any formal teaching of the urogenital examination after their introductory clinical skills sessions (Fig. 3).

\section{Discussion}

The urogenital examination is an essential clinical skill for practicing physicians in many fields. Although the introduction to this sensitive examination can be stressful for medical students in their pre-clinical training years, many researched initiatives have been explored and documented. These have been shown to reduce anxiety and improve both the students' comfort in clinical settings and their clinical expertise in performing the genitourinary examination..$^{3-6,8}$
This study found that Canadian medical students attending English-speaking programs are introduced to the urogenital physical examination in the first two years of their medical education. Preparatory resources, although available to students, vary wildly between schools. Urologists are often present to lead or facilitate the sessions, however, physicians and residents from other disciplines are commonly involved in the teaching. Surprisingly, students at more than 35\% of English-speaking Canadian medical schools do not perform a urogenital examination on a patient during their introductory clinical skills sessions. Additionally, not one respondent of our questionnaire was aware of formal urogenital examination teaching following these introductory sessions. This raises the concern that a medical student

\section{Following the initial teaching session, are students ever formally taught the examination again?}

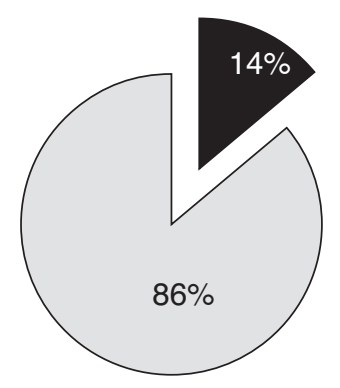

No $\square$ Maybe, dependent on student's schedule $\square$ Yes

Fig. 3. Students' potential for further teaching on examination. 
could potentially graduate from a Canadian medical school and enter residency without ever having performed a urogenital examination. This surprising result merits attention from undergraduate medical curriculum committees across the country.

Various approaches to support students through their initial experience with genital examinations have been found to successfully improve students' comfort and perceived ability..$^{3-6,8}$ The results of these studies, however, are based on questionnaires administered immediately before and after sessions specifically aimed to alleviate stress in an artificial environment, creating a huge bias. As students' focus is shifted to other areas of medical studies, their confidence in performing the urogenital examination diminishes. A recent study found that less than $40 \%$ of Canadian medical graduates felt confident they could identify an enlarged or nodular prostate on examination. ${ }^{2}$ The same study found nearly $60 \%$ of surveyed Canadian medical graduates were unsure they would be able to palpate an abnormal testicular mass. ${ }^{2}$ This is extremely worrisome and further demonstrates the urgent need to develop a competency-based genitourinary curriculum. Although significant focus has been placed on teaching strategies to decrease medical students' anxiety around their first genital examination, there has been little research into long-term outcomes in students' ability and confidence as they enter the clinical years of their training and how these can be improved.

There are a number of limitations to our study that may have underestimated the exposure medical students receive in the area of urogenital examination teaching. We contacted the pre-clerkship clinical skills coordinators across the country. These individuals are in charge of providing introductory clinical skills sessions to medical students. It is quite possible that students receive additional training during clinical rotations that is beyond the scope of these individuals and thus not captured by our survey. Further research into the amount of clinical exposure Canadian medical students receive in clerkship would be an interesting next step in this project. Additionally, our study only surveyed one representative from the main campus of each English-speaking medical school. It is possible that inclusion of satellite campuses and French-speaking schools may have provided additional insight into the methods in which the introductory urogenital examination is taught across the country.

If the number of male urogenital examinations performed by students during clinical training is truly the best determinant in their ability to perform this task by graduation, then ensuring students have the opportunity to complete this exam is essential. Although it may be unrealistic to propose mandatory clinical training with a urology department at many schools, there are other means to ensure adequate experience during clinical training years. A potential solu- tion would be requiring clinical task-logging during students' rotations in family medicine, emergency medicine, and surgery. Alternatively, supervised sessions to practice examination skills could be required during upper years of undergraduate medical studies for any students not directly rotating through a urology service. This would ensure each student receives formal clinical experience beyond introductory skills sessions. Finally, inclusion of the urogenital examination as possible OSCE stations for senior medical students would encourage students to maintain their knowledge and skill set prior to entering their residency years.

\section{Conclusion}

It has been well-established that the urogenital examination is a necessary skill for the accurate diagnosis and appropriate management of many medical conditions. Unfortunately, the undergraduate medical curriculum across Canada is still inconsistent in teaching this skill set, leaving many students underprepared to perform this task when entering their clinical training years. There have been a number of approaches described to decrease medical students' initial anxiety in completing this examination, however, increased attention is necessary to improve the accuracy of Canadian medical graduates in completing this essential skill. Proficiency in medical students' urogenital examination skills is urgently needed.

Competing interests: Dr. McApline's has no competing personal or financial interests. Dr. Steele has been an Advisory Board member for Astellas, Allergan, Fering, and Pfizer; a Speakers' Bureau member for Abbott, Astellas, and Pfizer; has received grants from Astellas, and Pfizer; and has participated in clinical trials for Astellas and Pfizer.

This paper has been peer-reviewed.

\section{References}

1. Powell HS, Bridge J, Eskesen S, et al. Medical students' self-reported experiences performing pelvic, breast, and male genital examinations and the influence of student gender and physician supervision. Acad Med 2006;81:286-9. http://dx.doi.org/10.1097/00001888-200603000-00022

2. Melnyk M, Ni A, Guerra L, et al. Teaching of the male urogenital exam in medical school: Are our students appropriately prepared for practice? Can Urol Assoc J 2010;4:86-7.

3. Isherwood J, Ashkir Z, Panteleimonitis S, et al. Teaching digital rectal examination to medical students using a structured workshop — a point in the right direction? I Surg Educ 2013;70:254-7. http://dx.doi.org/10.1016/i.jurg.2012.09.009

4. Fairbank C. Men's health: It is imperative to teach scrotal and rectal examinations. Clin Teach 2011:8:1014. http://dx.doi.org/10.1111/j.1743-498X.2010.00424.x

5. Howley LD, Dickerson K. Medical students' first male urogenital examination: Investigating the effects of instruction and gender on anxiety. Med Educ Online 2003;8:1-4. hittp://dx.doi.org/10.3402/meo. v8i.4336

6. Pugh $C M$, lannitelli $K B$, Rooney $D$, et al. Use of mannequin-based simulation to decrease student anxiety prior to interacting with male teaching associates. Teach Learn Med 2012;24:122-7. http://dx.doi.org $/ 10.1080 / 10401334.2012 .664534$ 
7. Hunter SA, McLachlan A, lkeda T, et al. Teaching of the sensitive examinations: An international survey. Open J Prev Med 2014;4:41-9. http://dx.doi.org/10.4236/ojpm.2014.41007

8. Ronn R, Smith W, Magee B, et al. Can online learning adequately prepare medical students to undertake a first female pelvic examination? J Obstet Gynaecol Can 2012;34:264-8. http://dx.doi.org/10.1016/ S1701-2163(16)35187-8
9. Robb A, Kopper R, Ambani R. Leveraging virtual humans to effectively prepare learners for stressful interpersonal experiences. IEE Virtual Reality 2013;19:662-70. http://dx.doi.org/10.1109/tvcg.2013.35

Correspondence: Dr. Kristen McAlpine, Department of Urology, Queen's University, Kingston, ON, Canada; kmcalpine@qmed.ca

\section{Appendix 1. Current practices in teaching the male urogenital examination to Canadian undergraduate medical students}

1) In which year is the clinical skill of male urogenital examination initially taught at your school?
a. Year 1
b. Year 2
c. Year 3
d. Year 4

2) In what setting is the clinical skill of the male urogenital examination taught?
a. Lecture based
b. Seminar (small group sessions)
c. 1:1:1 Student:Faculty:Patient
d. Online

3) What preparatory material do students have access to prior to their first male genital examination in a clinical setting?
a. Textbook
b. Lecture notes
c. Clinical skills handbook
d. Online module
e. Online video
f. Other; please explain:

4) Who teaches the male urogenital examination to medical students?
a. Family physicians
b. Urologists
c. Residents
d. Faculty tutors of any discipline
e. Nurse practitioners
f. Other; please explain:

5) Who/what do students examine during their introductory examination?
a. Models (prostate, male genitals)
b. Mannequins
c. Standardized patients
d. Genital teaching associates (trained community members who guide students and provide feedback during the examination)
e. Other; please explain:

6) What materials do students have to refer to following their initial male urogenital examination teaching?
a. Textbook
b. Clinical skills handbook
c. Online module
d. Online video
e. Access to models/mannequins
f. Session handouts

7) How are students tested or evaluated on material learned during the initial male genital examination teaching?
a. Possible OSCE stations
b. Specific clinical examination regarding male urogenital examination
c. Written examination
d. Online test
e. Reflective exercise, journal
f. They are not

8) Following the initial teaching of the male urogenital examination, are students ever formally taught the examination again?
a. Yes, repeat seminars/teaching sessions in clinical years
b. Maybe, depending on their clinical rotation schedule
c. No
d. Other; please explain:

9) Thank you for completing this survey. If you believe there is information regarding the teaching of the male urogenital examination at your school that was not well represented in this questionnaire please elaborate below. We appreciate any additional information you feel is relevant. 
Links to Provincial Formulary Criteria for XTANDI (enzalutamide) in chemotherapy-naïve $\mathrm{mCRPC}$ patients

Formulary: Alberta Outpatient Cancer Drug Benefit Program (Restrictions Exist) ${ }^{3}$

URL: http://www.albertahealthservices.ca/assets/ programs/ps-1025651-drug-benefit-list.pdf

Formulary: British Columbia Cancer Agency (Restrictions Exist) ${ }^{4}$

URL: http://www.bccancer.bc.ca/systemic-therapy-site/ Documents/ST\%20Update_October\%202015_Final.pdf

Formulary: Manitoba Drug Benefits and Interchangeability Formulary ${ }^{5}$

URL: http://www.gov.mb.ca/health/mdbif/bulletin85.pdf

Formulary: New Brunswick Drug Plans Formulary

(Special Authorization) ${ }^{6}$

URL: http://www2.gnb.ca/content/dam/gnb/

Departments/h-s/pdf/en/NBDrugPlan/

NewBrunswickDrugPlansFormulary.pdf

Formulary: Newfoundland and Labrador Prescription

Drug Program (Special Authorization) ${ }^{7}$

URL: www.health.gov.nl.ca/health/prescription/criteria/

Enzalutamide_Xtandi.pdf

Formulary: Nova Scotia Formulary (Exception Drug Status) ${ }^{8}$ URL: http://novascotia.ca/dhw/pharmacare/documents/ formulary.pdf

Formulary: Ontario EAP Reimbursement Criteria (chemotherapy-naïve patients) $^{9}$

URL: http://www.health.gov.on.ca/en/pro/programs/ drugs/pdf/frequently_requested_drugs.pdf

Formulary: P.E.I Pharmacare Formulary ${ }^{10}$

URL: http://www.gov.pe.ca/photos/original/hpei_

formulary.pdf?_ga=1.118540491.332354718.1457712241

Formulary: Régie de l'assurance maladie du Québec (RAMQ $^{\mathrm{TM}}$ ) List of Medications ${ }^{11}$

URL: https://www.prod.ramq.gouv.qc.ca/DPI/PO/

Commun/PDF/Liste_Med/Liste_Med/liste_med_

2016_03_24_en.pdf

Reimbursement Criteria for Chemotherapy-Naïve Patients:

- As monotherapy, for treatment of mCRPC in men:

- who are asymptomatic or mildly symptomatic after an anti-androgen treatment has failed; and

- who have never received docetaxel-based chemotherapy; and

- whose ECOG performance status is 0 or 1 .
Notes:

- The maximum duration of each authorization is 4 months.

- Upon subsequent requests, the physician must provide evidence of a beneficial clinical effect defined by the absence of disease progression. The ECOG performance status must remain at 0 or 1 .

- Authorization is given for a maximum daily dose of enzalutamide of $160 \mathrm{mg}$.

- It must be noted that enzalutamide is not authorized after abiraterone has failed if the latter drug was administered to treat prostate cancer.

Formulary: Saskatchewan Cancer Agency Drug Formulary (Step Access) $^{12}$

URL: http://www.saskcancer.ca/Formulary\%2002-12-2016

\section{Xtandi \\ capsules}

